\section{Caminhos da integração das universidades brasileiras e latino-americanas}

Sandra de Deus

Pró-Reitora de Extensão da

Universidade Federal do Rio Grande

do Sul, Brasil.

sdeus@terra.com.br
A 100 años de la Reforma Universitaria de 1918 /

Desafíos de gestión

RECEPCIÓN: 29/06/17

ACEPTACIÓN FINAL: 10/09/17

\section{Resumo}

A presente reflexão procura sobre alguns aspectos importantes para a integração das universidades latino-americanas, a partir de um pensar que não pode ser só da internacionalização mas da "latino-americanização", ou seja, um processo muito mais compreensivo e solidário calcado na extensão universitária, uma prática acadêmica exercitada em todas as universidades, Para tanto aponta organismos responsáveis pela integração político-econômica, entidades representativas das universidades e redes de extensão universitária. Aponta como traçado histórico a Reforma de Córdoba e lança olhares sobre a Conferência Regional de Educação Superior do ano 2018.

\section{Palavras-chave}

- Extensão universitária

- Educação superior

- Latino-americanização.

\section{Resumen}

El presente análisis pretende reflexionar sobre algunos aspectos importantes sobre la integración de las universidades latinoamericanas a partir de un pensamiento no solo de la internacionalización sino de la "latinoamericanización", o sea, un proceso más comprensivo y solidario basado en la extensión universitaria, una práctica realizada en todas las universidades. Para ello, señala organismos responsables de la integración político-económica, entidades representativas de las universidades y redes de extensión universitaria. Establece como recorrido histórico la Reforma de Córdoba y pone la mirada en la Conferência Regional de Educação Superior del año 2018.

Palabras clave

- Extensión universitaria

- Educación superior

- Latinoamericanización
Para citación de este artículo

De Deus, S. (2017). Caminhos da integração das universidades brasileiras e latino-americanas.

Revista +E versión en línea, 7(7), 98-103. Santa Fe, Argentina: Ediciones UNL. 


\section{Redes e redes de integração}

A integração latino-americana do ponto de vista político-econômico pode ser representada por iniciativas como o Mercado Comum do Sul (MERCOSUL), a União das Nações Sul-Americanas (UNASUL), a Aliança Bolivariana para os Povos da Nossa América (ALBA), a Comunidade de Estados Latino-Americanos e Caribenhos (CELAC). Já no âmbito da educação superior, a integração está assentada em entidades como a Unión de Universidades de América Latina y el Caribe (UDUAL); a Associação das Universidades do Grupo Montevidéu (AUGM); Associação de Universidades Amazônicas (UNAMAZ); Consejo Superior Universitario Centroamericano (CSUCA); Asociación de Consejo de Rectores de Universidades de Latinoamerica y el Caribe (ACRULAC) e o Espaço Latinoamericano e Caribenho de Educação Superior (ENLACES) criado em 2008 no marco da Conferência Regional de Educação Superior (CRES 2008) com o objetivo de construir um espaço comum de integração. ${ }^{1}$ A extensão universitária, também pensada no contexto latinoamericano, é representada pelas redes nacionais como a Red Nacional de Extensión Universitaria de la Argentina (REXUNI), o Fórum Nacional de Pró-Reitores de Extensão (FORPROEX), Red Ecuatoriana Universitaria de Vinculación con la Colectividad (REUVIC), Comité Ejecutivo de la Universidad Boliviana (CEUB), a Comissão de Extensão da Associação das Universidades do Grupo Montevidéu (Comissão Permanente de Extensão da AUGM) e outros além das redes de redes como União Latinoamericana de Extensão (ULEU), que conforma uma grande rede de extensão reunindo universidades, entidades regionais, instituições isoladas e redes representativas dos países em defesa da extensão universitária latino-americana e caribenha. Sob a orientação da ULEU foi realizado em 1994, em Matanzas (Cuba) o I Congresso Iberoamericano de Extensão Universitária concluindo que deveriam ser realizados novos encontros, sempre incorporando mais países, com o objetivo de implementar acordos bilaterais. Entende-se que neste universo deve se mover a extensão universitária no seu processo de internacionalização que busca o apoio mutuo na América Latina.

\section{Realidade brasileira}

O I Encontro de Pró-Reitores de Extensão das Universidades Públicas Brasileiras foi realizado na Universidade Nacional de Brasília em novembro de 1987 e culminou com a criação do FORPROEX (Fórum Nacional de Pró-Reitores de Extensão das Instituições Públicas de Educação Superior Brasileiras). Participaram do evento 33 universidades públicas, representadas por seus pró-reitores. Ao completar 30 anos, em 2017 o FORPROEX reúne 124 instituições públicas federais, estaduais e municipais. O Fórum de Pró-Reitores de Extensão é uma entidade voltada para a articulação e definição de políticas acadêmicas de extensão, comprometida com a transformação social para o pleno exercício da cidadania e o fortalecimento da democracia. Os objetivos desde a criação são: Propor políticas e diretrizes básicas que permitam a institucionalização, a articulação e o fortalecimento de ações comuns das Pró-Reitorias de Extensão e órgãos congêneres das Instituições de Ensino Superior Públicas Brasileiras; procurar manter a articulação permanente com representações dos Dirigentes de Instituições de Educação Superior, visando o encaminhamento das questões referentes às proposições do Fórum de Pró-Reitores de Extensão das Universidades Públicas Brasileiras; veicular a articulação permanente com os demais Fóruns de PróReitores, com o objetivo de desenvolver ações conjuntas que visem à real integração da prática acadêmica; defender o fortalecimento da atuação de redes de ações extensionistas visando balizar a construção de um projeto nacional em prol da inserção da extensão nos currículos de graduação e democratização de acesso e apoio às Instituições Públicas e Educação Superior, tendo em vista a inclusão social, sustentabilidade e valorização de diversidades —no primeiro encontro nacional de 2017 realizado em Porto Seguro, Bahia FORPROEX apresentou uma carta sustentando esse posicionameto; organizar estratégias de mobilização social, a partir do aprofundamento da interlocução com as comunidades e do desenvolvimento de metodologias participativas desencadeadoras de maior protagonismo dos movimentos sociais organizados e segmentos sociais na construção das políticas de extensão e defesa das Instituições Públicas de educação Superior, estimulando a realização de Fóruns Sociais simultâneos em todos os territórios; resistir às pautas desarticuladoras da concepção de ensino público superior no país por meio da reafirmação do seu papel e compromisso social, de modo que a extensão estabeleçase como diretriz transversal e inerente a todas as instâncias das Instituições Públicas de Educação Superior, consolidando a democracia participativa.

Os dirigentes do FORPROEX representaram o Brasil, em meados dos anos 90, na constituição da ULEU que conforma uma grande rede de extensão reunindo universidades, entidades regionais, instituições isoladas e redes representativas dos países em defesa da extensão universitária latino-americana e caribenha. Sob a orientação da ULEU foi realizado em 1994, em Matanzas (Cuba) o I Congresso Iberoamericano de Extensão Universitária concluindo que deveriam ser realizados novos encontros sempre incorporando
1) A nova Conferencia Regional de Educação Superior (CRES) será realizada em junho de 2018 em Córdoba,
Argentina, no marco dos 100 anos da Reforma de Córdoba. 


\section{G6}

Mais que procurar propostas para a integração através da extensão universitária

faz-se necessário pensar sobre a "latinoamericanização" das universidades da América Latina mais países com o objetivo de implementar acordos bilaterais. O Brasil foi sede do VIII Congresso Iberoamericano de Extensão realizado no Rio de Janeiro, em 2005, sob a coordenação da Universidade Federal do Rio de Janeiro (UFRJ). Durante a realização do X Congresso em Montevidéu (2009) iniciaram os debates visando alterar a denominação do evento que passou a ser Latinoamericano e Caribenho e não mais Iberoamericano. A declaração final do "Extenso 2009" denominou "integralidade del acionar universitário" para o desenvolvimento articulado do ensino, pesquisa e extensão como práticas universitárias que aproximem a universidade da sociedade na solução de problemas sociais relevantes e na busca do bem comum. O XIV Congresso Latinoamericano de Extensão foi realizado em junho deste ano (2017) em Managuá e o XV Congresso será realizado em 2019 no Paraguai.

Em 2011 os presidentes do FORPROEX, Cipriano Maia e da União Latinoamericana de Extensão Universitária (ULEU), Gustavo Menéndez definiram uma agenda de trabalho com o objetivo de fortalecer a integração das atividades de extensão na América Latina e no Caribe. O encontro de trabalho que ficou conhecido como "reunião de Porto Alegre" foi apoiado pela Universidade Federal do Rio Grande do Sul (UFRGS) e o MEC tratou de uma participação mais proativa do Brasil e da elaboração de uma agenda de trabalho para o fortalecimento da ULEU. Naquele momento demonstrou o esforço dos dois dirigentes em estabelecer, para além de um programa de atuação, um importante momento de troca e solidariedade com a participação de representantes da Argentina, Uruguai, Brasil, Cuba, Equador e Costa Rica.

\section{Comissão Permanente de Extensão da AUGM}

Em agosto de 2010 a Secretaria Executiva da AUGM realizou a reunião de formação do Comitê Acadêmico de Extensão. Em 2012 passou a ser Comissão Permanente de Extensão com os seguintes objetivos: promover a institucionalização e o reconhecimento da extensão como função substantiva da Universidade; fomentar a capacitação da extensão na comunidade acadêmica; impulsionar as publicações no campo da extensão. A Comissão Permanente de Extensão (CP) da Associação das Universidades do Grupo de Montevidéu (AUGM) ${ }^{2}$ conta com a participação dos representantes ( pró-reitores, delegados, secretários) de Extensão das universidades integrantes da Entidade.

A CP de Extensão da AUGM realiza duas reuniões anuais para definir agenda de trabalho e tratar do Congresso de Extensão que acontece a cada dois anos. O primeiro em 2013 teve como sede a cidade de Montevidéu (Uruguai) com o tema "Universidade e sociedade". O Segundo em 2015 na cidade de Campinas (São Paulo), tratando da "indissociabilidade entre ensino, pesquisa e extensão" e o terceiro Congresso em 2017, Santa Fe (Argentina) tendo como eixo central "democracia, direitos humanos e inclusão social: no caminho dos 100 anos da Reforma de Córdoba". A extensão universitária ganha evidência a partir de Córdoba com a criação das universidades populares em vários países da América Latina, particularmente no Peru e Cuba. Tünnerman Bernheim afirma que a manifestação de 1918 "fue la primera confrontación entre una sociedad que comenzaba a experimentar cambios en su composición interna y una Universidad enquistada en esquemas obsoletos" (1978:98).
2) A Associação das Universidades do Grupo de Montevidéu (AUGM) é uma rede de universidades públicas da Argentina, Bolivia, Brasil, Chile, Paraguay e Uruguay concebida em 1991 com a finalidade de responder em conjunto aos desafios que atravessavam a vida universitária no mundo (http://grupomontevideo.org). 


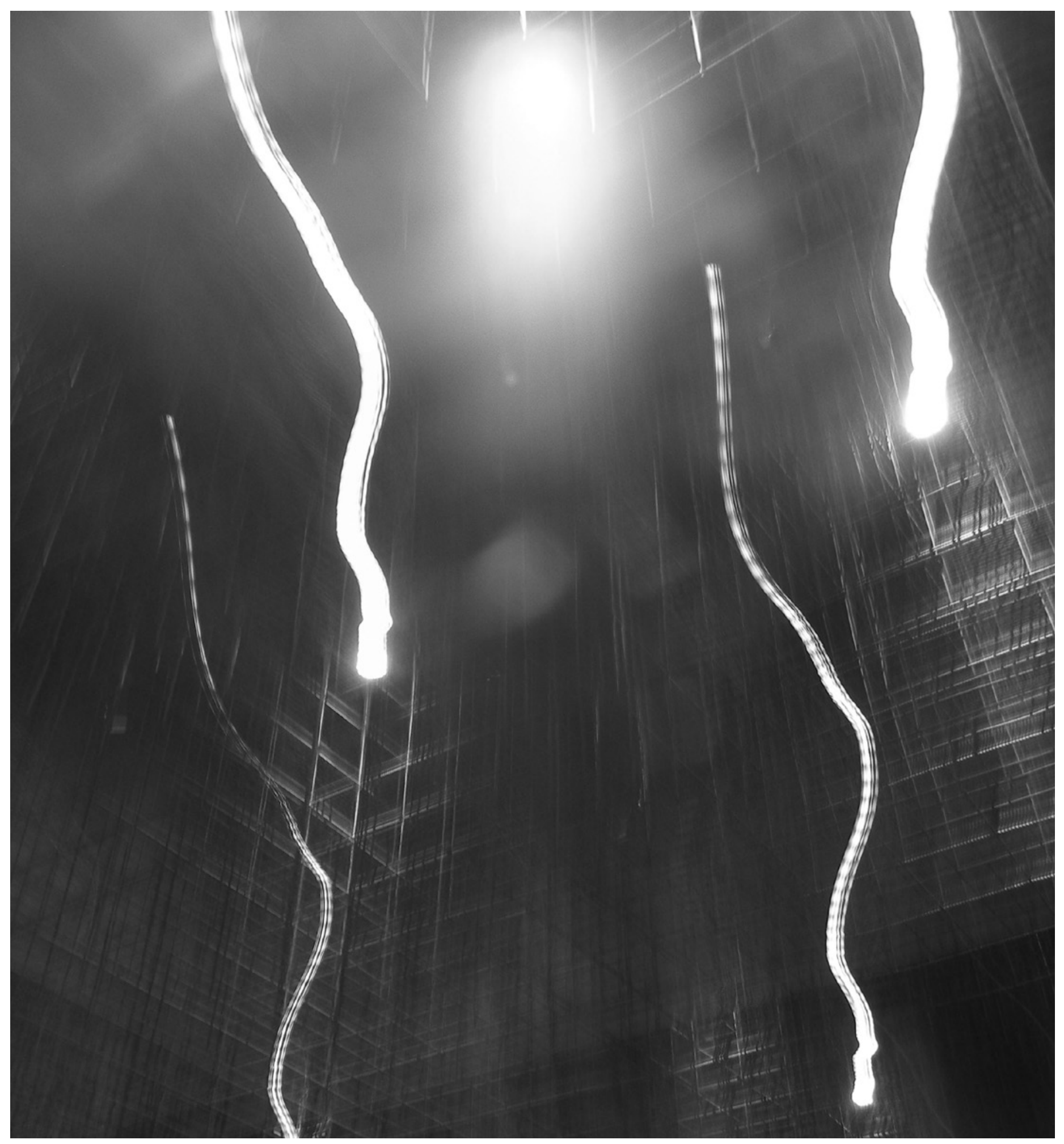

(C) Cecilia lucc 
Mais que procurar propostas para a integração através da extensão universitária faz-se necessário pensar sobre a "latinoamericanização" das universidades da América Latina e, dentro deste universo, encontrar na extensão universitária uma função fundamental para a concretização deste processo. A CP de Extensão da AUGM incorporou os 100 anos da Reforma de Córdoba na temática do III Congresso.

Em 2014 o Fórum Latino-americano de Educação Superior realizado na Universidade Federal de Integração Latino-Americana (UNILA) contou com a participação do estudioso António Nóvoa que apresentou para debate quatro apontamentos sobre a internacionalização da educação superior: a) a internacionalização tem servido "grandes negócios"; b) a internacionalização ganhase em casa; c) a internacionalização deve reforçar as nossas instituições e não tornar-nos ainda mais dependentes; e d) temos de fazer o dever de casa. Com estes apontamentos, Nóvoa (2015) nos diz que nossas universidades precisam ser infinitamente mais livres e mais abertas o que no caso brasileiro significa reforçar a política de extensão elaborada pelo Fórum Nacional de Próreitores de Extensão (FORPROEX) ${ }^{3}$ e a prática extensionista realizada nas instituição pública de educação superior atualmente regulamentada através de normas próprias de cada universidade.

Ao interpretar o pensamento de Nóvoa, é imprescindível pensar a extensão como parte do processo de internacionalização da universidade brasileira dentro de um contexto que inclui a flexibilização dos currículos de graduação permitindo que se cumpra a estratégia do Plano Nacional de Educação de inserir até dez por cento de créditos em extensão em cada curso ${ }^{4} \mathrm{e}$ adotar normas mais equilibradas para a progressão docente quando se trata da indissociabilidade ensino, pesquisa e extensão. ${ }^{5}$ Ignorar estes aspectos é optar pelo caminho do isolamento. Porém, é preciso, com certa compreensão tratar da "latino-americanização" da universidade latino-americana assegurando sempre que o chamamento de Córdoba se faz presente ao conclamar

"La juventud universitaria de Córdoba, por intermedio de su Federación, saluda a los compañeros de la América toda y les incita a colaborar en la obra de libertad que inicia" (Manifiesto Liminar, 1918).
Ao longo dos últimos 100 anos, estudos, interpretações, seminários e aproximações teóricas diante dos acontecimentos de 1918 foram se acumulando para ganhar mais força na última década, demonstrando a necessidade de um novo olhar sobre as relações entre as universidades latino-americanas e entre estas e a sociedade. A realidade política e econômica de cada país, os contextos educacionais específicos divididos entre público e privado, a inclusão de setores marginalizados que ingressam na educação superior a partir de propostas próprias de cada país, a organização estudantil e os recursos destinados para a educação superior são temas recorrentes seja nas reuniões dos organismos políticos-econômicos de integração, seja nos encontros das redes que reúnem universidades ou nos congressos de extensão universitária. A Conferência Regional de Educação Superior da América Latina e do Caribe (CRES 2018) a ser realizada em junho de 2018 em Córdoba no marco dos 100 anos da Reforma vai avaliar os resultados da Declaração de Cartagena 2008 que "expresa la necesidad de una mayor integración regional en el campo de la investigación científica y de la formación de recursos humanos calificados; instrumentos que promuevan la inclusión social. Igualmente expresa la preocupación por el crecimiento de los sistemas de educación superior en cada país, no solamente en números, pero en formas alternativas, como la educación a distancia, capaces de cumplir con la misión de democratizar el conocimiento. También promueve la cooperación entre los diversos segmentos sociales, destinada a estimular una efectiva transferencia del conocimiento y la implementación de efectivos instrumentos de cooperación con países desarrollados". (UNESCO-IESALC, 2008:s/n)

Para 2018 os objetivos sobre os quais a educação superior latino-americana e caribenha vai se dedicar são: reflexionar sobre la Educación Superior en la perspectiva del desarrollo humano sostenible para el siglo XXI; formular la Declaración de Educación Superior CRES 2018 como instrumento orientador para el desarrollo de la Educación Superior en la Región; establecer los lineamientos y hoja de ruta para la formulación del Plan de Acción para el período 2018-2028.
3) www.renex.org.br

4) 12.7) assegurar, no mínimo, $10 \%$ (dez por cento) do total de créditos curriculares exigidos para a graduação em programas e projetos de extensão universitária, orientando sua ação, prioritariamente, para áreas de grande pertinência social;

5) Art. 207. As universidades gozam de autonomia didático-científica, administrativa e de gestão financeira patrimonial, e obedecerão ao princípio de indissociabilidade entre ensino, pesquisa e extensão.

$\S 1^{\circ}$ É facultado às universidades admitir professores, técnicos e cientistas estrangeiros, na forma da lei (Incluído pela Emenda Constitucio- nal № 11, de 1996).

$\S 2^{\circ} \mathrm{O}$ disposto neste artigo aplica-se às instituições de pesquisa científica e tecnológica (Incluído pela Emenda Constitucional № 11, de 1996). 


\section{6}

O grande debate da extensão universitária é encontrar em cada instituição de educação superior mecanismos constitutivos para promover a inclusão social

\section{Considerações finais}

O grande debate da extensão universitária brasileira e latinoamericana, marco dos 100 anos de Córdoba, é encontrar em cada instituição de educação superior mecanismos constitutivos para promover a inclusão social e favorecer a mais solidária compreensão entre a diversidade cultural existente na América Latina. Em um universo marcado por diferenças regionais e legais cabe aos gestores da educação superior concentrar os esforços para cumprir ao longo dos anos os apontamentos da nova Conferência regional de educação Superior, mas muito especialmente, compreender que diante da atual situação regional nunca foi tão presente o pensamento de Boaventura de Sousa Santos:

"Temos o direito de ser iguais quando a nossa diferença nos inferioriza; e temos o direito de ser diferentes quando a nossa igualdade nos descaracteriza. Daí a necessidade de uma igualdade que reconheça as diferenças e de uma diferença que não produza, alimente ou reproduza as desigualdades". (2003:56)

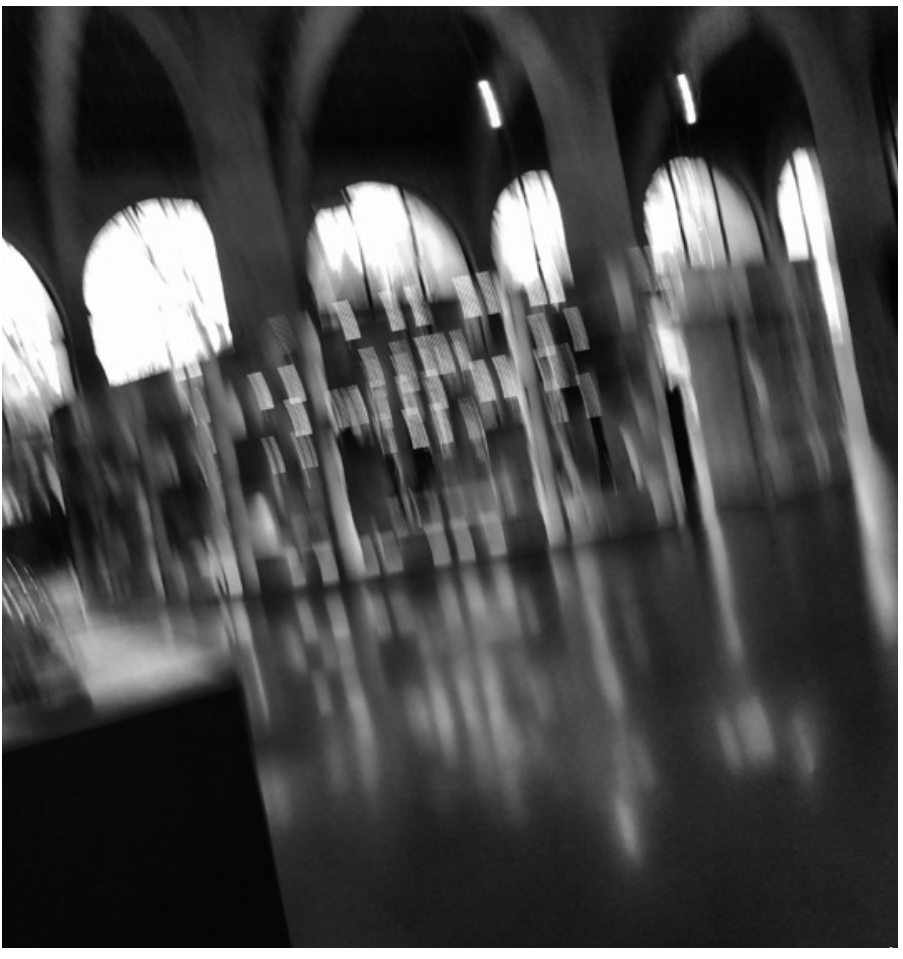

() Amanda Merino

\section{Referências bibliográficas}

AA. VV. (1985 [1918]). Manifiesto Liminar de la Reforma Universitaria de 1918. Buenos Aires: Ministerio de Educación y Justicia.

AUGM CP Extensão. http://grupomontevideo.org/sitio acessado em 25 de junho de 2017.

De Sousa, S. B. (2003). Reconhecer para libertar: os caminhos do cosmopolitanismo multicultural. Rio de Janeiro: Civilização Brasileira.

FORPROEX (2012). Política Nacional de Extensão. UFRGS. www.renex.org.br (acessado em 24/06/2017).

(2013.). Documento "Extensão sem Fronteiras" aprovado no Encontro Nacional do FORPOREX em Palmas (TO).

Fórum Latino-Americano de Educação Superior. OEI. PIXEL/São Carlos, 2015.

Nóvoa, A. (2015). O sentido da internacionalização: Na viagem. Na criação. No conhecimento. No encontro. Na paz com os outros e na paz com a Terra. Anais do Fórum Latino-americano de Educação superior, 67-73. São Carlos: OEI. PIXEL. Touraine, A. (1989). Palavra e sangue. São Paulo: UNICAMP/Trajetória Cultural. Tünnerman Bernheim, C. (1978). El nuevo concepto de extensión universitaria y difusión cultural y su relación con las políticas de desarrollo cultural em America Latina. Anuario de Estudios Centroamericanos, 4, 93-126.

UNESCO-IESALC (2008). Declaração de Cartagena Disponível em http:// www.unesco.org.ve/index.php?option=com_content\&amp;view=article\&amp;id=365\&amp; Itemid=423\&amp;lang=es (25/05/2017). 